\title{
POR QUE PESQUISA EM ENFERMAGEM
}

\section{Patricia Davis Toscano}

Um dos tópicos mais discutidos em enfermagem atualmente é o assunto de pesquisa. $O$ que é pesquisa em enfer magem e qual é a sua importância?

A fim de responder estas questōes, talvez seja melhor, antes de tudo, considerar o que é pesquisa em geral...

O que é pesquisa?

"Pesquisa pode ser definida como uma investiga çāo sistemática para acrescentar ao saber corrente um conheci mento que seja comunicável e verificável"1. E o uso de métodos padronizados na busca do conhecimento 2. Assim, pesquisa é uma forma específica de procura de conhecimentos, conduzida se gundo princípios lógicos. E a "resposta a quesiōes pela aplica çao de métodos científicos" 3 .

Portanto, a pesquisa sempre se inicia a partir de uma pergunta ou de um problema qualquer. Por exemplo, con siderando-se um fenômeno, deseja-se saber quais os fatos que o constituem para entāo descrevê-lo; pode-se perguntar a razão da quele fenômeno, ou seja, a sua "causa". bem como suas conse quências, isto $\dot{e}$, seus "efeitos", ou comparar dois fenômenos em relação a um terceiro.

Qualquer questão pode ser objeto de investiga ção científica, desde que obeỏeça a uma caractexística: deve ser tal que a observação ou a experimentação no mundo natural, que é a realidade empírica, forneça os dados necessários para a obten çäo de uma resposta. Questöes envolvendo julgamento de valôres, cais somo certo ou errado, bom ou ruim, objetivo e propósito são impróprias para o método de pesquisa; näo podem ser respon didas tão sòmente na base de informaçōes de fatos porque depen 
dem, pelo menos em parte, de uma decisão pessoal dêsse valor. Um exemplo de tal tipo de pergunta é: "Qual é a côr mais bonita, azul ou verde? Certamente nāo há fatos observados na natureza que possam responder a essa pergunta; "gôsto nāo se discute". Um outro exemplo envolvendo questōes de valôres seria: "Qual é o objetivo da enfermagem"? Uma pesquisa sobre esse assuntc pode retratar o que um certo grupo, como por exemplo o üas en: fermeiras de São Paulo, pensa ser o objetivo da enfermagem, mar nunca será a resposta à questão geral "qual é o objetivo da Enfer magem"; isto porque as informaçōes obtidas pela pesquisa nān são baseadas sòmente no mundo natural. Dentro do vasto cairpis do bem estar social e da saúde, os limites da área de Enferma. gem, como os de tôdas as áreas que compōem o bem estar \$ocia: (medicina, enfermagem, serviço social, etc.) são estabeiecidos pelo homem, como divisōes mais ou menos arbitrárias de uw do, com muita superposição de funçōes, cujo estudo requsir julgă mento de valôres e não sòmente observação do mundo naturaj.

As questōes envolvendo julgamento de valôres podem ser pesquisadas até o ponto em que possam ser desiobra das, de modo a que os elementos implícitos (relacionados a fatos e nāo a valôres) sejam tornados explícitos. Estes é que deven: ser estudados. Por exemplo: se alguém tentasse examinar a $r$ tina hospitalar de tomada de temperatura, pulso e respiraçäo c perguntar "Qual deveria ser a rotina de TPR nesta instituiçä.o o!: serviço ?"4 poder-se-ia desdobrar a questão "de valor" na.s ș guintes questōes "de fato".

- Qual é a atual rotina de TPR, tal como é descrita no miáuuai de rotinas?

- Qual é a atual rotina de TPR, tal como é desempenhada:

Quando é executada ?

Como é executada?

Quão precisa ela é quanto aos seguintes elemen tos de precisão:

material usado, desempenho da técnica, arota çōes no prontuário? 
- Qual é o padrão geral dos índices de temperatura em cada unidade

$$
\begin{aligned}
& \text { quantas elevaçōes de temperatura? } \\
& \text { quantos graus de elevação? } \\
& \text { quando as alteraçōes ocorrem? } \\
& \text { em que pacientes (diagnóstico, tempo de perma } \\
& \text { nência, etc.) } \\
& \text { poderia esta alteração de temperatura ser conhe } \\
& \text { cida de alguma outra forma? }
\end{aligned}
$$

- Quais são os canais de comunicação usados para relatar as alteraçōes de temperaturas?

Estas informaçōes sāo relatadas, por quem, pa ra quem, como e quando ?

Como é tal informaçäo úsada, que reação resul ta dela, por quem, por ordem de quem, quando, em que casos?

- Qual é o custo da rotina atual ? (material usado, tempo gas to em tôdas as fases e por que tipo de pessoal)

- O que estas pessoas consideram ser a rotina preferível para sua Unidade? Por que?

Com base em tais informaçōes e examinando a literatura dos conkecimentos científicos atuais com o TPR, a en fermeira estaria preparada para se reunir aos demais profissio nais da saúde envolvidos, neste caso médicos, a fim de, realìsti camente, considerar a rotina atual de TPR à luz das metas e dos propósitos estabelecidos para esta rotina, e determinar que modi ficaçōes, se fôr o caso, são indicadas para responder à questão "Qual deve ser a atual rotina de TPR deste serviço ou instituição?"

Em resumo, podemos dizer que a finalidade da pesquisa é responder a perguntas. Qualquar pergunta formulada ou qualquer problema, colocado de forma a que observaçōes ou ex perimentação no munaio natural possam prover a informação ne cessária, é legítima preocupação de pesquisa. Independentemente 
dos objetivos imediatos de cada pesquisa, a finalidade desta é adi cionar algo mais ao conhecimento já à disposição do homem.

Trataremos agora de outra parte de nossa defini ção: "Pesquisa é a procura de respostas por meio de métodos científicos" Uma assertiva essêncial da perspectiva científica é que há uma ordem básica na natureza e que esta ordem pode ser descoberta e compreendida. Por ordem na natureza quer-se di zer que há regularidade nos arranjos e sequências que fundamen tam e governam as.relaçōes físicas, biológicas e sociais de obje tos e acontecimentos, sendo êles relacionados entre si. Exemplos: as reações da criança hospitalizada diante da "perda" de seus pais; os padrōes de guerra das formigas; as reaçōes da partú riente na situaçāo de "stress" durante o parto; os efeitos do sono insuficiente sobre a faculdade de julgamento do indivíduo; as rea ções do átomo no bombardeamento nuclear; o ciclo vital da borbó leta. A partir desta ordem básica fundamental e de sua descober ta e verificação, emergem'leis, conceitos, e teorias do conheci mento científico 5 .

A metodologia científica ou de pesquisa foi de senvolvida como proteçāo contra o êrro, nas tentativas de desco berta e verificaçāo desta ordem na natureza; foi e continua a ser desenvolvida a fim de que seja aumentada a probabilidade de as in formaçōes recolhidas serem:

a) da mais alta qualidade possível, isto é, relevantes, exatas e sem viez ("bias")*;

b) utilizadas da mais extensa e completa maneira, para delas se extrairem conclusōes e recomendaçōes a respeito da questāo formulada. A metodologia de pesquisa não diz ao pesquisador como iniciar, o que fazer a seguir ou a que conclusōes chegar; oferece, porém, linhas mestras, su gestōes e técnicas para as várias fases de uma especula çāo científica, incluindo:

* "sem viez": não dirigida; coleta de dados feita de forma a que nenhuma resposta alternativa à questão seja favore cida. 
1. a formulação do problema de tal forma a poder ser sujeito a rigorosos testes;

2. a forma (exploratória, descritiva, ou experimental) e a es tratégia lógica do estudo (seus métodos e como executá-los);

3. a seleçāo da amostra;

4. o desenvolvimento dos instrumentos de medida;

5. o contrôle das observações na fase da coleta de dados, de forma tal que as informaçōes recolhidas sejam de fato reje vantes, exatas e sem viez;

6. análises, por meio de métodos de estatística descritiva*, das informaçōes obtidas a fim de descrever a amostra estudada;

7. interpretação desses dados por meio de métodos interferen ciais**, a fim de se aplicar essa descriçāo da amostra pá ra um grupo maior (a populaçāo);

8. conclusōes e recomendaçōes.

O objetivo ou propósito da pesquisa é, então, o de adicionar ou contribuir algo ao conhecimento corrente. Já que a pesquisa representa sempre uma jornada no desconhecido, pode ser que êste desejo seja irrealizável. "Pesquisa é orientada na direção da procura de respostas, que podem ou não ser encontra das"6. Todos os métodos que têm sido e continuam a ser desen

* Alguns dos métodos mais conhecidos de estatística descritiva incluem:

- descriçāo por categoria - tabelas e gráficos de distribuiçāo de frequência;

- descriçāo por abstração:

- tendência central (médio, mediana, módulo);

- variabilidade (extensão, variância e desvio padrāo);

- descrição pitórica por assoçiação - associação linear, asso ciação curvilínea, independência;

- descriçāo numérica de associą̧āo - coeficiente de correla çăo, momento de produto de correlação, nível de diferença de correlação, relaçao de correlação, etc.

** Métodos inferenciais incluem: uso de modêlos matemáticos de populações tais como curva normal, raiz quadrada, distribuição T, distribuiçáo $F$, etc., para considerar desvio padräo, érro pa dráo, probabilidade e significáncia. 
volvidos para a proteçāo contra o êrro não garantem os resultą dos. "Em outras palavras, os métodos protegem contra a otten ção de respostas erradas, mas não asseguram o encontro de res postas certas. Em verdade, a arte da investigação científica con siste em fazer a pergunta certa ou em testar a hipótese correta. Por pergunta "certa" quer-se dizer, simplesmente, aquela yue le va à respostas úteis, ou respostas que adicionam algo ao saber"

\section{Por que pesquisa em enfermagem}

Por que pesquisa é importante em enfermagem? Enfermagem como profissão é repleta de questões importantes.

Para ser eficiente, para se desenvolver, at:é $p_{d}$ ra manter sua posição como uma profissão a enfermagem Đ̄iecišı responder a essas questōes. Enquanto o atual objetivo de enfer: magem está ainda em processo de definição, pelo menos na prát: ca, parece ser o consenso entre os vários membros do caupu de saúde, incluindo a própria enfermeira, e a sociedade a que seirve: de que são funçōes da enfermeira ajudar o paciente a satisfázer adequadamente qualquer necessidade que afete o seu estado de saú de e possibilitar a aplicação das prescriçōes médicas para sobre pujar a doença e manter a saúde ${ }^{8}$. Naturalmente, dependando da situaçāo e dos recursos disponíveis, pode haver outras pessoas tais como assistente social, nutricionista, educador sanitário, téc. nico de enfermagem, auxiliar de enfermagem, atendente, cscritu rária, pessoal de limpeza, voluntária, etc. capazes de ajudar c paciente em tôdas ou algumas destas necessidades; mas, mesma quando a enfermeira não dá, ela mesma, completa assistência, certamente é sua a responsabilidade geral por essa assistência.

Na situação em que se encontra hoje a socieda de, com problemas de saúde maiores que os recursos disponíveis, a enfermeira, em seu trabalho, está colocada numa situaçāc cada vez mais difícil, pois, a realidade, dentro dos amplos limiies do exercício da profissão, estão incluídas tôdas as funçōes enựîi das na cura da doença e na manutenção da saúde, com exceção de 
diagnóstico e prescrição médica. A enfermeira não sòmente con tinua a ser responsável por aquelas áreas tradicionais da profis são, relacionados a medicação, tratamento, vigilância do estado do paciente, higiene geral e bem estar, educação sanitária, manu tenção de prontuários e responsabilidade pelo andamento geral do serviço; como, também, está sendo responsável por novas fun çōes; estas são funçōes que aumentam contìnuamente e sāo fré quentemente muito complexas, resultantes dos avanços de rovos métodos de diagnóstico e tratamento (por exemplo, cuidados do pa ciente de cirurgia cardíaca), bem como uma ampla área relativa mente nova de prevenção. Além disso, os recentes avanços nas ciências sociais e nas ciências do comportamento humano têm co locado tôdas essas funçōes sob uma nova luz, em que as necessi dades do paciente, nestas áreas de enfermagem e medicina, sāo agora reconhecidas como bem mais extensas e complicadas do que prèviamente se pensava. O homem é um sistema muito complexo de componentes interrelacionados e interdependentes, em que qua quer distúrbio, tal como a doença, afeta o todo e cada parte do todo, do mesmo modo que o todo e seus componentes afetam o dị túrbio e sua evolução. Do que, realmente, necessitam os pacien tes e como ajudá-los a satisfazer estas necessidades? mente para esta problemática que a enfermagem precisa encontrar respostas.

O que acontece se a enfermeira nāo procura tais respostas? Se ela não faz um esfốrço para ter em sua mente uma idéia clara do que deveria tentar conseguir, numa daua situa ção, e de como conseguí-la? se ela nāo reexamina tôdas as suąs atividades, planejadas em têrmos destas questōes ? Ela poderá fấ cilmente acordar um dia e descobrir que deu o melhor de si para levar avante as várias rotinas consideradas "necessárias" num dia de trabalho, mas nem sempre atualizadas; que muitas vêzes, as executar um trabalho, prendeu-se a mil e um detalhes desnecessá rios que estavam no seu caminho; como por exemplo, guardar um prontuário encontrado, procurar uma amostra gratis de medica mento, etc.; \& que, no entanto, deirou de dar atenção a problemas sérios, que requeiram assistencia de enfermagem, tais como: 
a mäe preocupada ainda não sabe, depois de quatro visitas à clíni ca, em que tempo e qual medicamento ela deve dar ao seu filho: a criança pequena, que se introverteu completamente depois de sua rebelião inicial, motivada pela ausência dos pais, continua intro vertida; a māe inexperiente, procurando dar de mamar ao seio para seu bebê ainda não teve sucesso; a velhinha que móra sòzi nha continua a retornar à clínica com curativo da semana anterior, embora devesse tê-lo trocado diàriamente.

A enfermagem precisa, consciente e continua mente, procurar respostas a questōes básicas da profissão.

Quais sāo os objetivos e os limites da profissāo da enfermagem ? Com base nestes objetivos, quais são as neces sidades de uma determinada população em uma situaçāo específi ca? Quais sāo os indicadores dessas necessidades? Como po dem ser resolvidas?

A fim de ser eficiente a. enfermeira necessita sa ber o que precisa realmente ser feito e como fazê-1o, decida ela delegar uma função a outra pessoa, exercê-la ela mesma, ou adiála para ocasiāo mais conveniente.

$\mathrm{Na}$ verdade, enfermagem nāo está completamen te sem respostas a estas questões. Elas existem nas páginas da literatura de enfermagem, nos livros de textos, nos manuais de rotina, nos cuidados intuitivos feitos por dedicadas enfermeiras e, mais recentemente, nas pesquisas de enfermagem e nas ciências sociais. Algumas dessas respostas já foram bem testadas pelo tempo, enquanto outras, ainda muito pouco. Raramente, entretan to, sāo estas informaçōes (teoria) apresentadas em forma sucinta e testadas (métodos de pesquisa) de maneira rigorosa, a fim de se determinar o que é realmente válido e o que não é; não podem, pois, tôdas as enfermeiras usar êste conhecimento em suas ativi dades profissionais, estejam elas dando assisténcia, supervisio nando ou ensinando outras pessôas a dá-la. Muitas decisōes rela cionadas à prática da enfermagem foram tomadas porque parecem ser o melhor caminho para se fazer o trabalho, tendo em vista os recursos disponíveis de tempo, dinheiro, pessoal, equipamento, 
etc. Tais consideraçōes são fatôres necessários, a fim de se deter minar quanto e como um certo objetivo pode ser realizado, mas, a menos que haja uma tentativa sistemática de estudar os proble mas, os julgamentos serão feitos e as conclusōes tiradas com ba se em observações e decisōes que são frequentemente pouco acura das ou exatas.

Sabendo que um fator importante no tratamento de criança, com uma determinada doença, é que ela recebe a dose adequada de medicamento, na hora certa, e julgando que um minu to e meio será tempo suficiente para ela explicar e a māe enten der, como e quando o medicamento deverá ser ministrado, ela po derá dicidir usar êste tempo para dar explicaçōes à mãe; pode en tretanto acontecer que o médico já tenha dado a explicaçāo e a mäē já tenha entendido; neste caso o tempo será demais para o fim a que ela se propôs; pode também acontecer que a māe nāo esteja em condiçāo de atender qualquer explicação e que precise ter as instruçōes por escrito para lêe-las mais tarde; neste caso ela pode rá utilizar o seu tempo providenciando que a ordem seja dada por escrito. Pode ser que esta inabilidade para compreender e reter uma explicação seja característica sòmente das maēs apreensivas. Assim sendo, quaie são as indicaçōes pelas quais a enfermeira re conhece que uma pessoa está apreensiva? A enfermeira pode tão sòmente basear suas decisōes nos conhecimentos que possui; sem estudar as questōes pertinentes a seu trabalho, tais conheci mentos poderão ser incompletos e êste trabalho poderá ser inútil.

A função primária da pesquisa de enfermagem é, pois, ajudar no desenvolvimento de guias ou fórmulas para a prá tica de enfermagem (teorias e conhecimentos científicos de enfer magem), mais articulados e testados, que permitirāo à enfermei ra alterar a realidade na direção desejada, isto é, obter o que ela planejou, numa determinada situação. Pesquisa nunca pode apre sentar uma fórmula ou teoria; é uma invenção da pessoa e oriun da de seus pensamentos e observaçōes; mas a pesquisa atua co mo um estimulante para a invençāo da teoria, sendo também um meio principal pelo qual a mesma, uma vez inventada, pode ser testada na realidade, a fim de se avaliar a sua eficiência ${ }^{9}$. 
A pesquisa não é contudo, o único meio para tes tar ou estimular a teoria; a prática profissional também conse gue tal objetivo. Qual é então a diferença entre as duas ? Embo ra ambas, pesquisa e prática, sejam atividades planejadas, que se realizam no presente, com o mesmo objetivo de ajudar o pacien te, a pesquisa tende a ser mais formal do que a prática.

O objetivo imediato ou a maneira pela qual a pes quisa realiza êsse objetivo geral é o de examinar o material apré sentado e testá-lo, à luz de suas pretençōes, para produzir conhe cimentos sobre cuidados de enfermagem; portanto, o plano é pré concebido e objetivamente designado para se ter em consideração e para controlar, tanto quanto possível, as variáveis pertinentes, existentes na situação de teste, a fim de proteger os resultados contra possíveis êrros. Para o início de seu trabalho, o pesquisa dor procura inspiração onde quiser, seja nos resultados de outras pesquisas, seja no trabalho profissional, ou mesmo na experiên cia quotidiana. Até a fase de tirar conclusōes e fazer recomenda çōes, sua contribuiçāo pessoal deverá ser sòmente na descoberta de novos caminhos, isto $\dot{e}$, tendo determinado e comunicado seu método, seus dados deverão ser repetidos por qualquer pessoa que diligentemente siga seu plano de trabalho.

Por outro lado, a prática de campo, embora sen do uma atividade planejada, tem como objetivo imediato não a có leta de novos conhecimentos mas sim o exercício de uma ativida de, a fim de efetivamente ajudar o paciente; portanto, esta práti ca poderia e deveria, se necessário, alterar a orientaçāo planeja da a fim de conseguir seu objetivo imediato. Havendo, geralmen te, menos esforçors conscientes, por parte da enfermeira prati cante, de identificar e considerar as variáveis pertinentes que es tão em jôgo no momento, é provável que fatôres relacionados à si tuação e que nela atuam possam passar despercebidos, daí resul tando uma avaliaçāo menos exata da sua atividade e de seus resul tados.

Nós podemos dizer, então, que tanto a pesquisa quanto a prática de campo serve como estimulante e como meio de teste de teorias ou planos de ação de enfermagem; mas que a pesquisa é um instrumento mais delicado. 
Pesquisa é um instrumento para aparar as ares tas de uma amostra ou testar as impurezas desta, ou investigar possíveis fontes de riqueza, como se se tratasse da amostra de um mineral; isto, porém, clepois que outro instrumento mais gros seiro porém igualmente eficiente, do ponto de vista práticc, já te nha cavado e encontrado a amostra. Em enfermagem, a saijedoria prática da enfermeira pode ser êsse mecanismo empírico mas igual mente essencial ${ }^{9}$. Teoria, oriunda da prática, é testada e re. finada pela pesquisa, a fim de ser dirigida de nôvo à prática, pos. sibilitando melhor assistência ao paciente ${ }^{10}$.

Concluindo, podemos sumarizar nossas cbserra. çōes relacionadas com o lugar da pesquisa em enfermagem un por que pesquisa em enfermagem, lembrando o conto da centoneia, en contrado no livro de Lazarsfeld ${ }^{11}$ sôbre métodos de pesquisa:

"Há uma história muito conhecida sobre a cents: peia que perdeu sua habilidade de andar quando the foi perguntacio em que ordem ela movia seus pés. Outros detalhes da históyia, en: tretanto, são sepultados em silêncio conspiratório. Antes de mais: nada, não há menção do fato de que a pergunta tenha vindo de urra pessoa (pesquisador) que queria melhorar a eficiência de cami. nhar da comunidade centípede. Também pequena atenção foi dada. às outras centopeias que participaram da investigação; nem tôdas reagiram com efeitos tão desastrosos; algumas foram capazes do. dar até respostas bem razoáveis. A partir destas, o investijgados trabalhou diligentemente para chegar aos princípios gerais de cor. portamento do andar das centopeias.

Quando o pesquisador finalmente publicon os achados, houve uma crítica generalizada de que êle tinha sùrneut relatado fatos que todo o mundo conhecia. Entretanto, formulando estes conhecimentos claramente e adicionando fatos não anterici: mente observados, a centopeia média da comunidade foi, eventuai mente, capaz de caminhar melhor, porque, depois de uma geração estes conhecimentos foram incorporados a livros de texto $c$ assim ficaram disponíveis para estudantes de um, menor nível de conhe cimentos. Em retrospecto, êste foi o resultado mais notável. Cêr tamente a grande bailarina centípede e outras artistas crcativas 
do andar continuam a depender de seus atributos hereditários (em enfermagem nós diríamos compreensão intuitiva) que não podem ser produzidas pelo sistema escolar; mas, o nível geral de cami nhar, caracteristico dos centípedes, foi melhorado e aqueles indi víduos com talento excepcional já começaram em nível mais alto e conseguiram realizaçōes criativas nāo igualadas no passado".

\section{Referências Bibliográficas}

1 - MACDONALD, M.E. - Social work research: a perspective. (In: POLANSKY, N., ed Social research. Chicago, Uni versity of Chicago Press, 1960. p. 1).

2-GREENWOOD, E. - Social work research: a decade of rep praisal. Social Work Review, 31: 312, sep. 1957.

3 - SELLTIZ, C. [and others] - Research methods in social rela tions. New York; Henry Holt, 1959. p. 2.

4-GARCIA, L. [e] DAVIS, P. - A rotina hospitalar do TPR e seu papel em bons e eficientes cuidados de enfermagem. Revista Brasileira de Enfermagem, 19 (4): 303-319, ago. 1966.

5 - JOHNSON, D. - Theory in nursing: borrowed and unique. Nursing Research, 17 (3): 207, may-jun., 1968.

6 -SELTTIZ, C. [and others] - Research methods in social relations. New York, Henry Holt, 1959. p. 4.

77 - MACDONALD, M.E. - Social work research: a perspective. (In: POLANSKY, N., ed Social research. Chicago, Uni versity of Chicago Press, 1960. p. 2).

8 - WIEDENBACH, E. - Clinical nursing: a helping art. New York, Springer, 1964.

9 - DICKOFF, J. [and] JAMES, P. - Researching research's ro le in theory development. Nursing Research, 17 (3): 204206, mai- jun., 1968. 
10 - DICKOFF, J. [and others] - A theory of theories: a position paper. Nursing Research, 17 (3): 297, mai-jun., 1968.

11 - LAZARDSFELD, P. [and] ROSENBERG, M. - The language of social research. GlenCoe, Free Press, 1955. p. 1.

12 - DICKOFF, J. [and others] - Practice oriented research. Nursing Research, 17 (6): 545, novidez., 1968.

TOSCANO, P.D. - Por que pes quisa em enfermagem. Rev. da Esc. de Enf. da USP. 4(1-2):41-53, mar-set. I970. 